\title{
Capsule Commentary on Phelan et al., Medical School Factors Associated with Changes in Implicit and Explicit Bias Against Gay and Lesbian People among 3492 Graduating Medical Students
}

\author{
Jeffrey L Jackson, MD MPH \\ Zablocki VAMC, Milwaukee, WI, USA. \\ $\mathrm{J}$ Gen Intern Med 32(11): 1248 \\ DOI: $10.1007 / \mathrm{s} 11606-017-4160-5$ \\ (c) Society of General Internal Medicine 2017
}

P helan and colleagues surveyed a random sample of 29 US medical schools to assess whether the medical school curriculum, role modeling, climate or contact with sexual minorities impacted medical students' potential bias against gay and lesbian people. ${ }^{1}$ They randomly sampled 5823 students during their first and last semester of medical school, assessing implicit sexual orientation bias using the sexual orientation implicit association test, excluding respondents who self-identified as not heterosexual or straight. In most schools, bias decreased during training, though in some bias increased. Predictors of reduced bias included favorable interactions with LGBT people, faculty modeling and witnessing micro-aggression against LGBT people. Students reporting less bias also reported feeling more comfortable and prepared to provide care to LGBT patients. It is interesting to speculate on whether they actually would provide better care, or just that they felt more comfortable seeing these types of patients. It is also interesting to note that the authors excluded the Uniformed Services University of the Health Sciences (USUHS), the nation's military medical school-because, according to the authors, "this school has unique characteristics that would have limited generalizability of study findings" - and also excluded students who reported their sexual orientation as other than heterosexual or straight. The authors make assumptions about the experiences of the military medical school trainees and also about LGBT students. It is interesting that an article exploring bias would demonstrate implicit bias in their own study design.
The authors conclude that medical schools could reduce bias by reducing negative role-modeling and improving the diversity climate, similar to numerous other studies that have explored bias, both explicit and implicit, against a number of different groups that have traditionally experienced discrimination. ${ }^{2-4}$ What we need in the field of discrimination, whether on the basis of gender, color or sexual orientation, is to move away from descriptive studies that document existance of the problem, and that provide associations which may or may not be causal, and to move toward testing interventions to see whether they can reduce these biases.

Corresponding Author: Jeffrey L Jackson, MD MPH; Zablocki VAMC, Milwaukee, WI, USA (e-mail: jjackson@mcw.edu).

\section{Compliance with Ethical Standards:}

Conflict of Interest: The author has no conflicts of interest with this article.

\section{REFERENCES}

1. Phelan SM, Burke SE, Hardeman RR, White RO, Pzredworski JM, Dovidio JF, Perry SP, Plankey M, Cuningham B, Finstad D, Yaezel M, van Ryn M. Medical school factors associated with changes in implicit and explicit bias against gay and lesbian people among 3492 graduating medical students. J Gen Intern Med. 2017 doi:10.1007/s11606-0174127-6

2. Devine PG, Forscher PS, Austin AJ, Cox WTL. Long-term reduction in implicit race bias: A prejudice habit-breaking intervention. J Exp Soc Psychol. 2012 48(6): 1267-1278.

3. Chapman EN, Kaatz A, Carnes M. Physicians and Implicit Bias: How Doctors May Unwittingly Perpetuate Health Care Disparities. J Gen Intern Med. 2013; 28(11): 1504-1510.

4. van Ryn M, Phelan SM, Burgess DJ, Dovidio JF, Herrin J, Burke SE, Nelson DB, Perry S, Yeazel M, Przedworski JM. Medical School Experiences Associated with Change in Implicit Racial Bias Among 3547 Students: A Medical Student CHANGES Study Report. J Gen Intern Med. 2015. 30(12):1748-1756. 